\title{
Vivências de prazer-sofrimento no contexto de trabalho dos professores
}

\section{Experiences pleasure-suffering in the context of teachers' work}

\section{Lêda Gonçalves de Freitas*}

Universidade Católica de Brasília, Brasília, Distrito Federal, Brasil

\author{
Emílio Peres Facas** \\ Universidade Federal de Goiás, Goiânia, Goiás, Brasil
}

\begin{abstract}
RESUMO
Este artigo apresenta o resultado de uma pesquisa sobre as vivências de prazer-sofrimento no trabalho, e sua relação com o contexto de trabalho de professores de uma escola pública, localizada no Paranoá, Distrito Federal. A pesquisa investigou o contexto de trabalho desses professores nas seguintes dimensões: Organização do Trabalho (OT), Condições de Trabalho (CT) e Relações Socioprofissionais (RSP). A Psicodinâmica do Trabalho foi a abordagem teórica utilizada para fundamentar o estudo. Entrevistas coletivas semiestruturadas e abertas foram realizadas com quatro grupos de professores e submetidas à análise de conteúdo, com base nos critérios de recorrência dos temas. Os resultados indicaram que os professores vivenciam prazer e sofrimento no trabalho, sendo o sofrimento mais presente. Os professores enfrentam, conscientemente, o sofrimento por meio de estratégias defensivas e de mobilização subjetiva que, por um lado, têm mobilizado e transformado aspectos do trabalho, mas, por outro, não têm conseguido mudar o contexto de trabalho.
\end{abstract}

Palavras-chave: Prazer-sofrimento, Estratégias defensivas, Mobilização subjetiva.

\begin{abstract}
This article presents the result of a research on the experiences of pleasuresuffering at work and its relation with the work context of teachers of a public school located in Paranoá, Federal District. The study investigated the work context these teachers in dimensions: Organization of Work (TOS), Working Conditions (CT) and relations Socio-Professional (RSP). THE psychodynamics of work was the theoretical approach used to justify the study. Open and semi-structured group interviews were conducted with four groups of teachers and submitted to content analysis, based on the criteria of recurrent themes. The results indicated that the teachers experience pleasure and suffering at work, and the suffering more than this. The teachers face, consciously, suffering by means of defensive strategies and subjective mobilization, on the one hand, have mobilized and transformed aspects of work, but, on the other, have not change the context of work.
\end{abstract}


Keywords: Pleasure-suffering, Defensive strategies, Subjective mobilization.

\section{I ntrodução}

O objetivo deste artigo é analisar a influência do contexto de trabalho dos professores nas vivências de prazer-sofrimento, na construção de estratégias de mediação e no processo de saúde-adoecimento. A abordagem que fundamenta este estudo é a Psicodinâmica do Trabalho, que tem como campo o conteúdo, a significação e a forma do sofrimento, situando sua investigação no campo do infrapatológico ou do pré-patológico. Tem por objetivo a análise de estratégias de mediação do sofrimento, individuais e/ou coletivas, utilizadas pelos trabalhadores em busca da saúde, considerando a subjetividade no trabalho como resultante da interação entre o sujeito e as dimensões do contexto de produção de bens e serviços. Para essa teoria, o importante é a compreensão de como os trabalhadores mantém o equilíbrio psíquico mesmo quando submetidos a condições de trabalho desestruturantes (MERLO, 2006; FERREIRA; MENDES, 2003; DEJ OURS, 1993).

Ferreira e Mendes (2003) esclarecem que, para compreender os conceitos da Psicodinâmica do Trabalho, é preciso levar em consideração o sujeito trabalhador, que pensa nas suas relações de trabalho e atribui um sentido às situações; e as situações de trabalho que modificam as "percepções desse trabalhador de si mesmo, dos outros e do próprio trabalho, tendo como resultado em uma subjetividade no trabalho que, por sua vez, pode ser diferente da subjetividade do indivíduo" (p. 52). É essa subjetividade que faz possível a construção do sentido do trabalho - de prazer e/ou sofrimento -, atribuído de forma compartilhada por um grupo de trabalhadores.

\section{Fundamentação teórica}

Segundo a Psicodinâmica do Trabalho, o trabalho é visto como estruturante psíquico e como uma atividade preponderantemente humana, de caráter intencional, finalístico e perpassado pela cultura (FERREIRA \& MENDES, 2003). Tem como função a busca de sobrevivência e a auto-realização. $O$ trabalho, quando não proporciona ao trabalhador a garantia de sobrevivência e a construção de sua identidade, pode resultar em sofrimento patogênico, e este, se não for enfrentado adequadamente, pode levar ao adoecimento. 
Para a Psicodinâmica do Trabalho, a saúde no trabalho está na busca pela integridade física, psíquica e social pelos trabalhadores em seu contexto de trabalho (CT) e se viabiliza pelo uso eficaz de estratégias para responder às diversidades do contexto de produção, possibilitando a ressignificação ou transformação do sofrimento no trabalho. Entende-se, assim, que a saúde não pressupõe a ausência deste, mas as possibilidades que o trabalhador terá para transformar tal vivência (MENDES, 2007; FERREIRA; MENDES, 2003).

A saúde, neste estudo, é compreendida, conforme a definição proposta por Ferreira e Mendes (2003), como sendo um processo de busca permanente dos trabalhadores pela integridade física, psíquica e social nos Contextos de Trabalho (CT). O CT caracteriza-se pela organização, condições e relações de trabalho, conforme estudo realizado por Ferreira e Mendes (2003) com auditores-fiscais da Previdência Social brasileira.

Segundo os autores, a organização do trabalho é constituída pelos elementos prescritos (formal ou informalmente) que expressam as concepções e as práticas de gestão de pessoas e do trabalho presentes no lócus de produção e que balizam o seu funcionamento. As condições de trabalho são constituídas pelos elementos estruturais que expressam as condições de trabalho presentes no lócus de produção e caracterizam sua infraestrutura, apoio e práticas administrativas. As relações socioprofissionais são constituídas pelos elementos inter-racionais que expressam as relações socioprofissionais presentes no lócus de produção e caracterizam sua dimensão social.

A atividade de trabalho é um processo dialético: de um lado, o sujeito trabalhador que dá sentido ao que faz; e de outro, as situações de trabalho que impactam sobre as percepções desse trabalhador em relação a todo 0 contexto de trabalho. Diante dessa dialética, 0 trabalhador pode ter vivências de prazer e ou sofrimento.

Para esta teoria, o sofrimento é inerente ao trabalhar. Origina-se na angústia vivida pelo trabalhador ao se deparar com a distância inevitável daquilo que foi prescrito (normas, regras, manuais, etc.) e a situação real de trabalho. A vivência de sofrimento decorrente desse confronto com 0 real pode ser criativa ou patogênica, a depender do destino que o trabalhador pode dar a ela. Quando o sujeito pode engajar o seu saber-fazer, utilizar sua inventividade para dar conta do hiato entre prescrição-real e ser reconhecido por isso, tem-se o sofrimento criativo. Este processo ressignifica o sofrimento e ocorre por meio da mobilização subjetiva, que será explicada mais a frente.

As vivências de sofrimento patogênico podem se expressar pelos males causados no corpo, na mente e nas relações socioprofissionais. Suas causas advêm do contexto de trabalho e manifesta-se por ansiedade, insatisfação, indignidade, inutilidade, desvalorização e 
desgaste no trabalho. O sofrimento no trabalho é compreendido por meio de vivências simultâneas de esgotamento emocional e falta de reconhecimento. $O$ esgotamento emocional se expressa por vivência de frustração, insegurança, inutilidade e desqualificação diante das expectativas de desempenho, gerando esgotamento, desgaste e estresse. A falta de reconhecimento se traduz pela vivência de injustiça, indignação e desvalorização e pelo não-reconhecimento do trabalho.

As vivências de prazer, em contrapartida, surgem do bem que o trabalho produz no corpo, na mente e nas relações sociais. As suas causas originam-se das dimensões que estruturam o CT. As vivências de prazer se manifestam por meio da gratificação, da realização, do reconhecimento, da liberdade e da valorização no trabalho. Constituem-se como um dos indicadores de saúde no trabalho por possibilitarem a estruturação psíquica, a identidade e a expressão da subjetividade no trabalho, de modo a viabilizar as negociações, a formação de compromisso e a ressonância entre o subjetivo e a realidade concreta de trabalho.

O CT, nas suas três dimensões (organização do trabalho, condições de trabalho, relações socioprofissionais), influencia o prazer e o sofrimento, que são constitutivos da subjetividade do trabalho, por meio de vivências que retratam o sentido dado ao trabalho como resultante da interação entre condições subjetivas (dos sujeitos) e objetivas (da realidade de trabalho).

Nesse contexto, o trabalhador despende energia individual e coletivamente na busca de dar conta da realização da atividade. Sendo assim, ele poderá vivenciar prazer e ou sofrimento. Caso predomine o sofrimento, e este não seja ressignificado e transformado em prazer, restará ao trabalhador o uso de estratégias defensivas.

As estratégias de defesas geralmente são inconscientes. Conforme Ferreira e Mendes (2003), são individuais e ou compartilhadas em grupo de trabalhadores e se apresentam sob a forma de negação e ou racionalização. Na negação, expressada em comportamentos de isolamento, desconfiança, individualismo e de consequente eliminação do coletivo de trabalho, o trabalhador não admite o próprio sofrimento. $\mathrm{Na}$ racionalização, há uma suavização da angústia, do medo e da insegurança presentes no contexto de trabalho. Manifesta-se por comportamentos de apatia, resignação, indiferença, passividade, conformidade e de controle sobre pessoas.

A utilização destas estratégias defensivas pode ter uma função positiva, uma vez que colabora para o equilíbrio psíquico e favorece a adaptação às situações de desgaste emocional pelo confronto permanente do profissional com seu contexto de trabalho. No entanto, pode mascarar o sofrimento psíquico quando provoca estabilidade psíquica artificial, adquirindo assim uma dimensão 
patológica que interfere tanto no atendimento aos objetivos do trabalho, quanto na vida social dos profissionais. Neste caso, quando as estratégias de defesas são utilizadas de modo permanente podem se tornar ineficazes e levar a doenças (FACAS, 2009).

O sofrimento, contudo, nem sempre levará ao adoecimento. Pode constituir um indicador de saúde, por ser uma vivência de afetos dolorosos e um mobilizador para as mudanças das situações que fazem sofrer, quando é ressignificado pelo uso eficaz de estratégias de mobilização subjetiva.

As estratégias de mobilização favorecem a saúde ao permitir a ressignificação do sofrimento por meio da transformação das situações de trabalho. São modos de ação coletiva dos trabalhadores que se operacionalizam por meio do espaço público de discussão e da cooperação, com vistas a eliminar o custo humano negativo do trabalho, ressignificar o sofrimento e transformar em fonte de prazer e bem-estar a organização, as condições e as relações socioprofissionais (FERREIRA; MENDES, 2003).

Para os autores Dejours, Abdoucheli e Jayet (1994), a mobilização subjetiva caracteriza-se pelo uso dos recursos psicológicos do trabalhador, que se engaja na dinâmica de construção e de evolução da organização do trabalho lançando mão de sua subjetividade e da sua inventividade, e pelo espaço público de discussões sobre o trabalho. Neste espaço, o trabalhador ressignifica suas representações sobre sua atividade ao falar sobre os aspectos que causam sofrimento no cotidiano do trabalho. A mobilização subjetiva é também um processo de busca de prazer, pois o trabalhador busca uma transformação das situações geradoras de sofrimento em situações que gerem prazer. Nesse espaço as regras de ofício são construídas e as opiniões podem ser formuladas e declaradas (FACAS, 2009; ROSSI, 2008).

Mendes e Morrone (2002) esclarecem que esse coletivo de trabalho é criado em uma situação, e não dado pela empresa. Baseia-se em regras que vão além da técnica e que organizam as relações entre as pessoas. Possui uma dimensão ética, com a noção de justo/injusto, não constituem normas ou regulação e se portam pelo julgamento de estética e qualidade do trabalho. Esses julgamentos se dão de duas formas: pela conformidade do trabalho - que deve ser realizado, respeitando as normas - e pela originalidade - que diferencia os sujeitos e valoriza a singularidade e a personalização. É este último que dá acesso à identidade que é construída no coletivo.

Para Ferreira e Mendes (2003), o espaço público de discussão constitui-se no local em que o trabalhador expressa livremente seus sentimentos em relação ao sofrimento vivido. A cooperação possibilita a ação coordenada e conduz à construção de ações comuns com base na confiança e na solidariedade. 
A mobilização subjetiva depende da dinâmica entre o que o trabalhador oferece como contribuição e a retribuição desta que, quando não ocorre, leva o trabalhador a se desmobilizar. Essa retribuição, de natureza simbólica, é dada por meio do reconhecimento. $\mathrm{O}$ valor de retribuição simbólica dado pelo reconhecimento surge da produção do sentido dado à vivência do trabalho. A construção desse sentido, que vai ao encontro das expectativas do trabalhador em relação à sua realização profissional, pode transformar o sofrimento em prazer (FACAS, 2009; MENDES, 2007; DEJ OURS, 2004).

Conforme estudos sobre a saúde dos professores, realizados por Scalco, Pimentel e Pilz (1996), Codo e Vasques-Menezes (1999), Fonseca (2001), Gomes (2002), Sobrinho (2002), Porto et al. (2004), o trabalho docente tem uma sobrecarga que produz custos à saúde e gera problemas físicos e psíquicos. Segundo tais estudos, as doenças que mais têm acometido os professores são as do aparelho respiratório e as relacionadas às lesões por esforços repetitivos e distúrbios osteomusculares relacionados com o trabalho (LER/DORT). Além desses males, os estudos indicam que a síndrome de Burnout tem sido identificada nos professores. Os docentes acometidos dessa síndrome perdem o entusiasmo e sentem-se, cada vez mais, frustrados. Num estágio mais avançado da síndrome, segundo as pesquisas, o professor chega ao desespero, sente-se depressivo e com vontade de abandonar o trabalho.

Para Esteve (1999), há um mal-estar na profissão docente que surge com a transformação do seu papel em virtude das exigências impostas pelo atual contexto social. Segundo o autor, os principais elementos que têm causado esse mal-estar são: a) o acelerado avanço do saber, que faz o professor buscar aprendizagem permanente; b) a constatação de que a realidade se transformou e a impossibilidade de continuar mantendo objetivos que já não correspondem ao contexto social; c) as exigências das famílias pelo sucesso dos filhos, diante de uma realidade que não garante ao final dos estudos sucesso profissional aos alunos, tendo em vista o quadro de desemprego estrutural e o acirramento da competitividade no mercado de trabalho. Esse mal-estar docente, conforme o autor, opera-se por meio do absenteísmo, do estresse e das doenças às vezes fingidas na busca de se ausentar momentaneamente da sala de aula, até aparecerem as verdadeiras doenças, como neuroses ou depressões.

Em síntese, a literatura aponta que há um sofrimento na categoria dos professores, o qual é motivado pela peculiaridade da profissão. De acordo com Fonseca (2001), o trabalho do professor é cansativo; há desgaste, pois se leva muito trabalho para casa; há excessiva pressão dos pais e da direção da escola; há novas exigências 
demandadas a esses profissionais, conforme destacado anteriormente por Esteve (1999).

\section{Procedimentos metodológicos}

\subsection{Perfil dos participantes}

A pesquisa foi realizada em uma escola pública do Distrito Federal, localizada na Região Administrativa do Paranoá. A escola oferece educação infantil e ensino fundamental ( 1 으 ao 5 o ano). Tem no seu quadro de pessoal 42 professores.

Os participantes da pesquisa foram 17 professores, sendo 16 concursados e 1 contratado, temporariamente. Em sua maioria, são do sexo feminino $(76.5 \%)$, com ensino superior completo na área de pedagogia, idade entre 30 e 55 anos, mais de 5 anos de docência e carga horária em torno de 8 horas diárias.

\subsection{I nstrumentos}

Foram realizadas quatro entrevistas coletivas semiestruturadas, com base nos seguintes temas:

. Organização do trabalho.

. Condições e relações de trabalho.

. Sentimentos relacionados ao trabalho.

. Estratégias para o enfrentamento das adversidades do contexto de trabalho.

\subsection{Procedimentos}

A pesquisa foi divulgada para todos os professores da escola, sendo que 17 servidores se mostraram interessados em participar do estudo.

As entrevistas foram realizadas entre os meses de setembro e dezembro de 2007. Cada entrevista teve a duração de mais ou menos duas horas.

\subsection{Análise dos dados}

Para a análise dos dados, aplicou-se a técnica de análise de conteúdo (BARDIN, 1977), que, por suas características, permite explicar os aspectos simbólicos e reais no processo de interação do sujeito com a sua realidade de trabalho.

As formas de categorização foram padronizadas com base nos critérios de recorrência dos temas, ou seja, passando, primeiramente, pela coleta de verbalizações e, em seguida, agrupando-as em temas. 
Com o material organizado por temas, construíram-se as categorias específicas. Após a elaboração das categorias específicas de cada uma das entrevistas, definiram-se seis categorias sínteses, as quais subsidiaram as interpretações e também os resultados.

\section{Resultados}

A apresentação dos resultados está organizada em quatro tópicos: 1) Contexto de trabalho dos professores; b) Vivências de prazer e/ou sofrimento; c) Estratégias de enfrentamento do sofrimento; d) Danos à saúde. Em cada tópico são destacadas as categorias sínteses que foram elaboradas a partir das entrevistas. As categorias são descritas e ilustradas com as verbalizações dos participantes.

\subsection{O contexto de trabalho dos professores}

Os resultados sobre o contexto estão aglutinados em três categorias sínteses: organização do trabalho, condições de trabalho e relações socioprofissionais, as quais serão apresentadas a seguir.

\subsubsection{Organização do trabalho}

Quanto à organização, o trabalho dos professores pesquisados consiste em atividades de planejamento, sala de aula, estudos e reuniões com a direção da escola. Os professores cumprem uma carga horária semanal de 40 horas de trabalho, sendo 8 horas diárias: 5 horas em sala de aula e 3 horas em atividades na coordenação pedagógica.

[...] enfim, dentro do planejamento que a gente tem daquela semana, a gente planeja toda segunda-feira.

Chegando aqui na escola, vou, recebo as crianças, vou para a sala de aula, e aí não saio quase para nada, às vezes nem para tomar um cafezinho. Então é o tempo inteiro na sala de aula.

Cinco horas a professora falando? E a gente acaba fazendo isso, falando, falando o tempo inteiro, e trabalha isso, e trabalha aquilo [...] o tempo inteiro na cabeça da criança? $[\ldots]$.

Nas horas destinadas à coordenação, o professor faz o planejamento das aulas, participa de reuniões para discutir assuntos da escola e realiza atividades de formação continuada. O planejamento das atividades é feito semanalmente e coletivamente, tendo como referencial as orientações da Secretaria de Educação e da direção da 
escola. Para que o planejamento aconteça, os professores se organizam nas séries em que atuam.

É [...] na coordenação, eu procuro planejar a aula do dia seguinte, mas é mais para fazer uma reflexão de como é que foi a aula anterior.

Tem a segunda-feira que tem reunião, a quarta também, então às vezes é uma reunião para trocar de planejamento, semanal, ou mensal, ou uma atividade mais [...] que envolva o mês inteiro, ou semanal.

De acordo com as entrevistas, nota-se que o cotidiano da sala de aula é desenvolvido conforme o planejamento elaborado na coordenação e que a rotina de sala de aula ocorre a partir da vontade dos professores e das necessidades dos alunos, exceto para os professores que atuam no Projeto "Se Liga"1 , que tem uma dinâmica própria e um planejamento pronto vindo da instituição que 0 gerencia.

\begin{abstract}
Aí essa rotina a gente pode estabelecer de acordo com a nossa própria vontade, e com a coordenação, com a assistente que faz o planejamento junto com a gente, e agenda tudo lá, [...] os horários, se não der nesse horário geralmente a gente estabelece outra rotina, a gente mesmo com os alunos, e a gente vem vendo as necessidades deles e vai trabalhando conforme as necessidades deles.
\end{abstract}

Os professores organizam as cinco horas de trabalho com os alunos da maneira que consideram mais apropriada. O trabalho em sala de aula envolve atividades coletivas com os alunos e, em alguns momentos, atividades individualizadas. $\mathrm{O}$ atendimento individualizado ao aluno é, muitas vezes, impossível de ocorrer, visto o grande número de alunos por turma.

Agora, a dificuldade é você fazer esse trabalho, esse acompanhamento mais individualizado, porque são 35 alunos ali para receberem a informação.

Não bastasse essa organização no trabalho, os professores sentem-se pressionados pelos pais e pelo governo; são cobrados excessivamente; e buscam solitários resolver as inúmeras demandas do cotidiano de ser professor. Queixam-se que o trabalho não termina quando acaba o horário das aulas, pois em casa não conseguem se desligar dos problemas das crianças e da escola, isso quando não levam trabalho para casa para dar conta de toda a demanda do fazer docente.

Eu tenho essa aqui uma das grandes dificuldades da sala de aula, que o professor é um trabalho solitário. Porque ele se 
vê, assim, impotente em algumas questões e não se sente na liberdade de compartilhar aquilo com outro.

Ah, eu saí do trabalho, acabou, vou para casa. Você não desliga, não tem como.

\subsubsection{Condições de trabalho}

Em relação às condições de trabalho, os professores da educação infantil, em particular, reclamam da falta de monitores e do número excessivo de alunos em sala de aula, o que dificulta manter uma atenção individual e um trabalho de qualidade com as crianças. Avaliam ainda a falta de um grupo de apoio, formado por orientadores, psicólogos e professores nas áreas de artes e educação física, para dar suporte e minimizar as dificuldades do professor em sala de aula.

Acho que [...] 20 crianças, no máximo 25 tinha que ter numa sala dessas. Numa turma de Pré. Não é possível tantos alunos.

De acordo com os professores, a escola não dispõe de material didático adequado para as atividades pedagógicas. A qualidade do giz enviado pela Secretaria de Educação, por exemplo, não é satisfatória; ele é muito duro, deixando a mão do professor dolorida após o trabalho.

\footnotetext{
Eu acho muito precário né? A gente não tem material didático adequado a cada núcleo [...] não tem mais lápis, não tem mais borracha, então é difícil para a gente trabalhar. Fica liso e um giz que quando você termina sua mão está doendo. O giz. Nós não temos giz. O giz que nós temos é um giz duro que quando você termina de escrever no final giz você está com a mão dolorida.
}

Os professores destacam ainda que o ambiente físico é precário. Faltam melhores banheiros, parques e salas de aula mais adequadas. Também não há brinquedos e computadores para diversificar as aulas e melhorar o trabalho do professor.

Por fim, os professores afirmam ser desvalorizados não somente pela questão salarial, mas também pela falta de respeito dos governantes em relação às condições precárias de trabalho. E ainda destacam que muitos pais não reconhecem o trabalho que eles desenvolvem com as crianças na escola.

É um dos pontos de maior frustração para mim, nesses dez anos, é a [...] o comportamento da Secretaria com os professores, de total desrespeito, de total falta de consideração. A Secretaria eles realmente mostram, o 
Governo, o GDF mostra que eles não têm a educação como prioridade.

\subsubsection{Relações socioprofissionais}

Os professores destacam que o relacionamento com os alunos, sobretudo com as crianças, é satisfatório, embora alguns deles relatam ter problemas com alunos adolescentes, que costumam agredi-los com insultos.

Não tenho problema com as crianças, só com os pais, de vez em quando né? Que eles já chegam assim, não quer saber [...] só vem deixar.

A relação dos professores com os colegas é marcada pelo trabalho em grupo, e sua união, e pela troca de idéias na busca de resolução dos problemas. Segundo os professores, o diálogo com a direção da escola é recente e conquistado por meio da pressão dos próprios docentes. A direção é um pouco distante, mas faz o que é possível para a escola.

Aqui na creche toda a gente tem um ótimo relacionamento. Esse ano, pelo menos, a gente nunca teve problemas assim de briga, de intriga em colega, que eu percebesse, [...].

Quando ela não dialoga, aí o trabalho, ele trava. É [...] ultimamente, nesses últimos anos, a direção, eles têm dialogado com os professores.

A maior queixa dos professores diz respeito à relação com os pais. Muitas vezes, eles chegam à escola alcoolizados e os insultam. Quando acontecem problemas com os alunos, os pais não procuram nem saber, já chegam com ofensas para cima dos professores. Ademais, a postura da Secretaria de Educação, segundo os docentes pesquisados, é de total desrespeito e falta de consideração para com eles.

Por exemplo, uma criança caiu machucada, você tem que saber como chegar no pai para conversar, você não pode chegar assim de qualquer jeito "ah, caiu e machucou". Eles não levam isso como uma coisa normal. Eles levam isso como uma ofensa, o professor não cuidou, o professor não foi responsável. Então com os pais aqui é difícil da gente lidar. Uma boa maioria, pelo menos, é muito difícil.

\subsection{Vivências de prazer e ou sofrimento}


Neste tópico, serão destacados os resultados referentes às categorias de prazer e de sofrimento no trabalho.

\subsubsection{Vivências de prazer}

O prazer dos professores pesquisados está relacionado com o desempenho das crianças no seu processo de aprendizagem, pois isto faz com que eles se sintam satisfeitos e motivados para o trabalho.

É o dia a dia. É bom, é agradável, é legal você ver o progresso da criança, hoje eu estava olhando os caderninhos deles, primeiro dia de aula estava lá, lá na primeira [...] e aí você vai vendo o movimento da criança, a melhora da criança diante daquele problema que ela apresentava, $[\ldots]$.

Os professores demonstram prazer também na confiança que sentem dos colegas e no reconhecimento dos alunos. Além disso, os elementos de autonomia para organizar o processo de trabalho geram satisfação e minimiza o sofrimento causado pela intensa demanda de trabalho. Exceto para os professores do projeto "Se Liga", os quais recebem o planejamento das atividades pronto. "O dia a dia com as colegas é muito agradável".

\subsubsection{Vivências de sofrimento}

Conforme a pesquisa, o sofrimento dos professores no trabalho provém da sobrecarga de trabalho; da intensa pressão de pais e governo pela aprendizagem dos estudantes; das más condições de trabalho; da falta de respeito dos gestores da educação; da falta de interesse dos alunos; dos obstáculos para trabalhar com os alunos que precisam de mais atenção; e das inúmeras dificuldades dos estudantes, tendo em vista que a comunidade do Paranoá apresenta um alto índice de pobreza.

\footnotetext{
Mas o trabalho do professor é muito desgastante, porque ela trabalha no período da manhã, eu trabalho à tarde. Então, quando a gente chega aqui na escola, na verdade, a gente já trabalhou o dobro em casa, ou pelo menos a metade.

Então isso me estressa, eu fico estressada. A criança vem sem tomar banho, é aluno de primeira série, até segunda, terceira, quarta $[\ldots]$.
}

Os estudantes, muitas vezes, têm problemas de aprendizagem, e muitos pais não têm interesse pela educação dos filhos, fato comum em comunidades carentes econômica e culturalmente. Nesse contexto, os problemas da comunidade ecoam no ambiente escolar e dificultam o trabalho do professor. 
Eu começo, assim, a indisciplina, essa falta de respeito dos alunos e a falta de parceria com os pais. Acho que a família está deixando tudo por conta da escola e a escola também é feita de seres humanos e não tem o pozinho mágico para resolver.

\subsection{Estratégias de mediação do sofrimento}

As estratégias de mediação do sofrimento compõem uma categoria de análise. Entretanto, os resultados serão evidenciados em dois grupos: estratégias defensivas e estratégias de mobilização subjetiva e coletiva.

\subsubsection{Estratégias Defensivas}

Para enfrentar o sofrimento, os professores utilizam estratégias defensivas. Buscam se envolver emocionalmente com as crianças e agem como psicólogos, dentistas e médicos; compram material pedagógico para os alunos, a fim de não prejudicar o seu trabalho.

Os professores se consideram super-poderosos. Fazem de tudo para não deixar a peteca cair, o que implica dar conta de tudo. Utilizam a afetividade como forma de envolver os alunos nos estudos. E esta afetividade que desenvolvem com os alunos em sala de aula compensa a frustração que sentem quando não resolvem certos problemas.

Na verdade, a gente tem de ser super-poderosa. A gente tem de dar conta de tudo e não deixar a peteca cair não.

Então eu me cobro muito e acabo cobrando muito também dos meus alunos. Mas eu acho que o resultado final, por essa cobrança, foi boa.

Enfim, os professores demonstram consciência do sofrimento no trabalho, mas, em função das defesas, suportam as situações desconfortáveis como podem.

\subsubsection{Estratégias de mobilização subjetiva e coletiva}

Há na escola um trabalho de grupo, em que os professores constantemente trocam idéias na busca de resolução de problemas. Isto possibilita a construção do espaço público de discussão e a transformação da realidade de trabalho.

[...] a gente consegue contornar a situação com a ajuda mútua, com o "jeitinho" que a gente dá aqui.

\subsection{Danos à saúde}

Em relação aos danos à saúde, o trabalho, por ser fisicamente cansativo, leva os professores a apresentarem problemas de insônia 
e ou de excesso de sono. O cansaço gerado pelo trabalho acaba também com a voz dos professores. Muitos deles também se queixam de dores, sobretudo na coluna vertebral, precisando, muitas vezes, tomar relaxante muscular.

Energeticamente, o ambiente me vampirizou. Porque o meu estado emocional ficou abalado na maioria do tempo.

As exigências emocionais vivenciadas em função do contexto socioeconômico dos alunos conduzem os professores a estados de muita tristeza, ou até mesmo de depressão. Os professores se doam muito ao trabalho e à escola, e mesmo assim nunca é o suficiente. Isto faz com que o emocional deles fique constantemente abalado.

Uns com problema de insônia, outros com problema de excesso de sono, estresse mesmo, problemas assim relacionados ao psicológico da gente no corpo [...] sentindo mesmo excesso de cansaço mesmo.

\section{Discussão}

Os resultados sobre o contexto de trabalho dos professores investigados indicam que há precariedade na organização, nas condições e nas relações socioprofissionais. As inúmeras exigências para o fazer docente, a pressão de pais e governo pela aprendizagem dos estudantes, o número excessivo de alunos em sala, a precariedade de instrumentos de trabalho e a carência material dos alunos contribuem significativamente para as vivências de sofrimento dos professores.

Os resultados sobre a organização de trabalho dos professores ratificam os estudos realizados por outros pesquisadores, (SCALCO, PIMENTEL; PILZ, 1996; CODO; VASQUES-MENEZES, 1999; FONSECA, 2001; GOMES, 2002; SOBRINHO, 2002; PORTO ET AL. 2004), os quais revelam as inúmeras exigências para o trabalho docente e a pertinência de condições de trabalho que não favorecem o cotidiano do trabalho em sala de aula.

Ressalta-se que a sociedade contemporânea, ao mesmo tempo em que produz um discurso de educação para todos, não consegue possibilitar aos professores, profissionais que são os maiores responsáveis pela aprendizagem da sociedade, as condições de trabalho e a valorização social, elementos essenciais para o exercício de uma carreira profissional.

Contudo, apesar das exigências da profissão e da falta de condições de trabalho, o estudo mostra que os professores vivenciam o prazer no trabalho que se manifesta pelo reconhecimento dos alunos, pela satisfação em ver o desenvolvimento dos estudantes, pela autonomia 
para organizar o trabalho e pela relação saudável entre os colegas. Tais vivências constituem-se indicadores de saúde no trabalho, ao proporcionar a estruturação psíquica, a identidade e a expressão da subjetividade no trabalho (FERREIRA; MENDES, 2003). Por isso, o contexto de trabalho investigado favorece a mobilização subjetiva, tendo em vista que há espaço para a ação coletiva dos trabalhadores, por meio do planejamento semanal e coletivo do trabalho que realizam (DEJ OURS, ABDOUCHELI; JAYET, 1994).

Os dados apontam para um espaço público de discussão e de cooperação entre os trabalhadores investigados, contribuindo para a ressignificação do sofrimento e, consequentemente, a vivência de prazer no contexto de trabalho. Esse espaço se mostra na troca e compartilhamento de experiência entre os professores e em ações como se articular para levantar dinheiro para compra de materiais.

É justamente por meio deste olhar dos colegas, possibilitado pela cooperação entre os trabalhadores e, principalmente, pela possibilidade das ações coletivas, que a subjetividade do professor se fortalece. A retribuição simbólica, possibilitada pelo reconhecimento dos pares, possibilita dar sentido a algo que gera angústia justamente por estar fora da lógica de trabalho do sujeito. Esse olhar do outro serve também como um espaço de validação do saber, por meio da possibilidade de ter seu trabalho reconhecido, de ver sua solução sendo aprovada e utilizada pelos pares. Assim, o sujeito tem a oportunidade de buscar e garantir sua integridade psíquica, de se inscrever, de constituir sua identidade.

Já o sofrimento patogênico evidencia-se por meio de vivências de estresse, frustração, esgotamento, sobrecarga e desgaste. Para enfrentar 0 sofrimento, os professores compartilham, conscientemente, de estratégias defensivas. Observa-se que os docentes racionalizam as dificuldades por meio da suavização dos problemas. Envolvem-se, sobremaneira, com as crianças e buscam dar conta de tudo. Essa tentativa de ser super-poderoso é uma das saídas que esses profissionais encontram para racionalizar 0 sofrimento que emerge das falhas naquilo que não depende exclusivamente deles - falta de materiais, situação social dos alunos. A exigência do contexto de trabalho leva o professor ao pensamento de que "não tem como" ser diferente, uma vez que o trabalho precisa ser feito. Além disso, essa estratégia permite uma sustentação da imagem do professor como um profissional diferenciado, como aparece na fala de um dos entrevistados: "[...] educação não é para qualquer um [...] tem que ser muito forte".

No presente estudo, observa-se que a particularidade da escola, ao receber estudantes com inúmeras carências materiais, impõe aos professores demandas para além das reveladas em outras pesquisas. Destarte, o fato dos professores terem que comprar materiais didáticos para que possam realizar o seu trabalho revela a luta 
desses profissionais para darem conta das suas obrigações. No entanto, expõe um Estado que, na Constituição de 1988 normatizou a educação como um direito, mas não tem conseguido estender direitos sociais ao conjunto da população brasileira. Nesse ínterim, os professores se sentem solitários diante de um cotidiano de sala de aula altamente exigente numa sociedade que cada vez mais requer desses profissionais o desenvolvimento da aprendizagem de crianças, adolescentes e jovens.

De todo modo, a pesquisa revela um paradoxo no trabalho dos professores investigados, nota-se que há indicadores de saúde, ao mesmo tempo em que existem indicadores de adoecimento. Os indicadores de saúde dos professores investigados se viabilizam pela busca constante por integridade física, psíquica e social e pela utilização de estratégias de mediação do sofrimento para dar conta das contradições do contexto de trabalho.

Os indicadores de adoecimento revelam-se pelos danos físicos e psicológicos. O uso excessivo da voz e a postura inadequada surgem neste estudo como elementos causadores de danos físicos à saúde dos professores. As queixas de dores musculares são recorrentes entre os docentes. Os danos psicológicos manifestam-se pela intensa tristeza e, em alguns casos, até pela depressão.

Tais resultados confirmam as pesquisas de Scalco, Pimentel e Pilz (1996), Codó e Vasques-Menezes (1999), Fonseca (2001), Gomes (2002), Sobrinho (2002), Porto et al. (2004), as quais indicam que o trabalho docente apresenta uma alta sobrecarga e, por conseguinte, produz problemas físicos e psíquicos. Nessas pesquisas, os autores afirmam que os professores, em função do desgaste causado pelo excessivo trabalho e pela pressão dos pais e da escola pela aprendizagem dos estudantes, expõem-se à síndrome de Burnout, ao estresse, à depressão e a tensões e ansiedades.

Neste estudo, portanto, percebe-se a coabitação do prazer e do sofrimento, sendo este último o que predomina. Deduz-se que o contexto de trabalho investigado favorece os riscos de adoecimento, uma vez que o sofrimento prevalece em pontos centrais do fazer docente. Nota-se que o adoecimento, por um lado, está contido pelo sucesso da utilização das estratégias de mediação do sofrimento e, por outro lado, está presente em função da sobrecarga e das exigências da escola, dos pais, da Secretaria de Educação e do governo.

\section{Considerações finais}

A presente pesquisa corrobora com estudos anteriormente citados ao indicar que o sofrimento dos professores é proveniente da sobrecarga de trabalho; da pressão de pais e do governo; e das más condições 
de trabalho. Todo esse contexto acarreta danos físicos (problemas na voz e LER/DORT) e danos psicológicos (depressão e ansiedades), conforme destacado anteriormente.

As pesquisas com professores indicam que os riscos para a saúde no ambiente de trabalho derivam dos movimentos repetitivos, da exposição ao pó de giz, do uso excessivo da voz e da postura inadequada (SCALCO, PIMENTEL; PILZ, 1996; PORTO et al., 2004). Ademais, há os riscos para a saúde em função da desvalorização profissional, do cansaço, da ausência de capacitação para lidar com questões próprias do trabalho, da exigência de manter a disciplina em sala de aula, da sobrecarga de trabalho extraclasse, do desgaste, do volume da carga cognitiva e também da excessiva pressão dos pais e da direção da escola pela aprendizagem dos alunos.

A pesquisa revela que os professores investigados buscam a saúde por meio da mobilização coletiva. A possibilidade de troca de experiências entre os trabalhadores e a construção coletiva de estratégias para transformar aquilo que, na organização do trabalho, causa angústia, ajuda a sustentar a saúde e a identidade do professor. Entretanto, o contexto de trabalho, em vários aspectos, não dá conta de garantir a saúde nos seus aspectos físicos, psíquicos e sociais. Nesse sentido, urge, por parte da gestão, ações que visem a mudar o contexto de trabalho e a diminuir a sobrecarga e a pressão no trabalho do professor.

Assim, a redução do número de alunos em sala de aula, a melhoria das condições materiais da escola e o apoio de psicólogos e assistentes sociais no trabalho do docente com os alunos em sala de aula contribuirão, significativamente, para tirar o professor da solidão em que se encontra na relação ensino-aprendizagem e na responsabilidade de dar conta da aprendizagem dos estudantes, diante de um contexto de enorme exigência por escolaridade.

Outras ações dizem respeito ao próprio professor. É fundamental que ele reconstrua sua formação iluminista de resolver sozinho todos os problemas e de "dar conta de tudo" e começar a compartilhar com a direção da escola, pais e colegas o sofrimento advindo do seu trabalho cotidiano em sala de aula. Segundo o aporte teórico utilizado no estudo, o reconhecimento do trabalho - ponto central para a saúde do trabalhador - se dá em dois níves: (a) o julgamento de beleza do trabalho, proferido pelos pares e; (b) o julgamento de utilidade do trabalho, proferido por chefias, subordinados e clientes. Ainda que, via coletivo de trabalho, o julgamento de beleza seja contemplado, é preciso que se garanta, também, o reconhecimento por parte da direção da escola, pais e alunos. Para isso, é preciso que o professor também rompa com esse papel de super-profissional e torne inteligível seu trabalho para os outros.

Por fim, a construção da qualidade de vida do professor requer uma parceria com a sociedade. A exigência de os professores buscarem 
cada vez mais uma aprendizagem permanente é um discurso forte nos diversos campos sociais. Sendo assim, o Estado, os pais, os estudantes e os mais variados organismos da sociedade civil precisam cuidar bem dos seus professores.

\section{Referências}

BARDIN, L. Análise de conteúdo. Lisboa: Editora 70, 1977.

BARROS, P. C.; MENDES, A. M. Estratégias de mediação do sofrimento psíquico de trabalhadores terceirizados da construção civil. PSICO - Universidade São Francisco, Itatiba, v. 6, n. 1, p. 81-108, 2001.

CODO, W.; VASQUES-MENEZES, I. Educar, educador. In: CODO, W. (Org.). Educação: carinho e trabalho. Petrópolis, RJ: Vozes/Brasília; CNTE/UNB: Laboratório de Psicologia do Trabalho, 1999, p. 37-47.

DEJ OURS, C. A loucura do trabalho: estudo de psicopatologia do trabalho. São Paulo: Cortez, 1980/1987.

- Inteligência operária e organização do trabalho: a propósito do modelo japonês de produção. In: HIRATA, H. (Org.). Sobre o modelo japonês. São Paulo: Editora Universidade de São Paulo, 1993, p. 281-309.

- ABDOUCHELI, E. Itinerário teórico em psicopatologia do trabalho. In: DEJ OURS, C.; ABDOUCHELI, E.; JAYET, C.; BETIOL, M. I. S. (Coords.). Psicodinâmica do trabalho: contribuições da escola dejouriana à análise da relação prazer, sofrimento e trabalho. São Paulo: Atlas, 1994, p. 119-145.

DEJOURS, C. A banalização da injustiça social. São Paulo: Fundação Getúlio Vargas, 1999a.

$\overline{1} \overline{9} \overline{9} \bar{b}$.

. Fator humano. Rio de Janeiro: Fundação Getúlio Vargas,

- Travail, souffrance et subjectivité. Sociologie du Travail, Paris, v. 43, n. 2, p. 329-340, 2000 a.

. Un regard de psychanalyste sur la guerre économique. Le

Journal de L'Ecole de Paris, Paris, v. 24, p. 7-15, 2000b.

. L'évaluation du travail à lépreuve du réel: critique dês fondements de l'évaluation. Paris: INRA, 2003.

Subjetividade, trabalho e ação. Revista Produção, São Paúlo, edição especial, v. 3, n. 14, p. 27-34, 2004a.

Activisme professionnel: masochisme, compulsivité ou àliénation. Travailller: Revue Internationale de Psychopathologie et de Psychodynamique du Travail, Paris, v. 11, p. 25-41, 2004b.

. Addendum da psicopatologia à psicodinâmica do trabalho. In: LANCMAN, S.; SZNELWAR, L. I. (Orgs.). Christophe Dejours da psicopatologia à psicodinâmica do trabalho. Rio de Janeiro: Fiocruz; Brasília: Paralelo 15, 1993/2004, p. 47-104. 
Nouvelles formes de servitude et suicide. Travailller: Revue Internationale de Psychopathologie et de Psychodynamique du Travail, Paris, v. 13, p. 53-75, 2005.

ESTEVE, J. M. O mal-estar docente: a sala de aula e a saúde dos professores. Bauru, SP: Edusc, 1999.

FACAS, E. P. Estratégias de mediação do sofrimento no trabalho automatizado - estudo exploratório com pilotos de trem de metrô do Distrito Federal. 2009. 115f. Dissertação (Mestrado em Psicologia Social, do Trabalho e das Organizações) Universidade de Brasília, Brasília, 2009.

FERREIRA, M. C.; MENDES, A. M. Trabalho e riscos de adoecimento: o caso dos auditores-fiscais da Previdência Social brasileira. Brasília: Ler, Pensar e Agir, 2003.

FONSECA, C. C. O. P. $\mathbf{O}$ adoecer psíquico no trabalho do professor de ensino fundamental e médio da rede pública do Estado de Minas Gerais. 2001. 226f. Dissertação (Mestrado em Engenharia de Produção) - Programa de Pós-Graduação em Engenharia de Produção, Universidade Federal de Santa Catarina, Florianópolis, 2001.

FREITAS, L. G. O processo de saúde e adoecimento dos professores que atuam em ambiente virtual. In: MENDES, A. M. (Org.). Psicodinâmica do trabalho: teoria, método e pesquisa. São Paulo: Casa do Psicólogo, 2007.

FREITAS, L. G. Saúde e processo de adoecimento no trabalho dos professores em ambiente virtual. 2006. 235f. Tese (Doutorado em Psicologia) - Universidade de Brasília, Brasília, 2006.

GOMES, L. Trabalho multifacetado de professores e professoras: a saúde entre limites. 2002. 118f. Dissertação (Mestrado em Desenho Industrial) - Fundação Oswaldo Cruz, Rio de Janeiro, 2002.

MENDES, A. M. Cultura organizacional e prazer-sofrimento no trabalho: uma abordagem psicodinâmica. In: TAMAYO, A. (Org.). Cultura e saúde nas organizações. Porto Alegre: Artmed, 1994, p. 59-76.

. Comportamento defensivo: uma estratégia para suportar o sofrimento no trabalho. Revista de Psicologia, Fortaleza, v. 13/14, n. 1/2, p. 27-32, 1996.

. MORRONE, C. F. Vivências de prazer-sofrimento e saúde psíquica no trabalho: trajetória conceitual e empírica. In: MENDES, A. M.; BORGES, L. O.; FERREIRA, M. C. (Orgs.). Trabalho e transição, saúde em risco. Brasília: Editora UnB, 2002, p. 25-42.

MENDES, A. M.; FERREIRA, M. C. Validação do inventário sobre trabalho e riscos de adoecimento - ITRA. In: CONGRESSO REGIONAL DA SOCIEDADE INTERAMERICANA DE PSICOLOGIA, 2006, Havana. 
. Da psicodinâmica à psicopatologia do trabalho. In: MENDES, A. ${ }^{-}$. (Org.). Psicodinâmica do trabalho: teoria, método e pesquisas. São Paulo: Casa do Psicólogo, 2007, p. 29-48.

MERLO, A. R. C. Psicodinâmica do trabalho. In: CATTANI, A. D.; HOLZMANN, L. (Orgs.). Dicionário de trabalho e tecnologia. Porto Alegre: UFRGS Editora, 2006, p. 215-218.

PORTO, L. A.; REIS, I. C.; ANDRADE, J. M.; NASCIMENTO, C. R.; CARVALHO, F. M. Doenças ocupacionais em professores atendidos pelo Centro de estudos da Saúde do Trabalhador (CESAT). Revista Baiana de Saúde Pública, Salvador, v. 28, n. 1, p. 33-49, 2004.

ROSSI, E. Z. Reabilitação e reinserção no trabalho de bancários portadores de LER/ DORT: análise psicodinâmica. 2008. 270f. Tese (Doutorado em Psicologia). Brasília, Universidade de Brasília, Brasília, 2008.

SCALCO, M. A. G.; PIMENTEL, R. M.; PILZ, W. A. A saúde vocal do professor: levantamento junto a escolas particulares de Porto Alegre. Pró-Fono Revista de Atualização Científica, São Paulo, v. 8, n. 2, p. 25-30, 1996.

SOBRINHO, F. P. N. O stress do professor do ensino fundamental: 0 enfoque da ergonomia. In: LIPP, M. (Org.). O stress do professor. Campinas, SP: Papirus, 2002, p. 81-94.

\section{Endereço para correspondência \\ Lêda Gonçalves de Freitas}

QS 07 Rua 800 Lt. 01 BI. B Ap. 505, Bairro Águas Claras, Taguatinga, CEP

71971 540, Brasília, DF, Brasil

Endereço eletrônico: ledag@ucb.br

Emílio Peres Facas

Rua 235, S/N - Faculdade de Educação - UFG, Setor Leste Universitário, CEP - 74605-050, Goiânia, GO, Brasil

Endereço eletrônico: emiliopf@gmail.com

Recebido em: 13/12/2010

Reformulado em: 07/11/2011

Aceito para publicação em: 11/11/2011

Acompanhamento do processo editorial: Rita Maria Manso de Barros

\footnotetext{
Notas

* Professora da Universidade Católica de Brasília, Brasília, Brasil. Doutora em Psicologia Social e do Trabalho pela Universidade de Brasília.

** Professor da Universidade Federal de Goiás, Goiânia, Brasil. Mestre em Psicologia Social, do Trabalho e das Organizações pela Universidade de Brasília.

${ }^{1}$ Programa de correção de fluxo escolar desenvolvido pelo Instituto Ayrton Senna. O "Se liga" destina-se a alunos com distorção idade/série, não alfabetizados, das quatro primeiras séries do Ensino Fundamental.
} 